Volume 1 Nomor 1

\title{
ANALISIS RELASI NEGARA DAN AGAMA DALAM PERSPEKTIF PANCASILA
}

\author{
Evy Septiana Rahman \\ evy_arifien@yahoo.co.id \\ Dosen Institut Agama Islam Negeri Metro Lampung
}

\begin{abstract}
ABSTRAK
Sesuai dengan prinsip Ketuhanan Yang Maha Esa maka posisi agama menjadi roh atau spirit dari keutuhan Negara Kesatuan Republik Indonesia. Dengan diterimanya Pancasila sebagai dasar negara secara tegas dijelaskan bahwa Indonesia bukan negara yang berdasarkan suatu agama dan bukan pula negara yang memisahkan agama dan negara melainkan Negara Pancasila yang mengakui dan mensakralkan keberadaan agama, bukan hanya Islam namun termasuk Kristen, Budha, Hindu dan Khong $\mathrm{Hu} \mathrm{Cu}$ sebagai agama resmi Bangsa Indonesia. Relasi negara dan agama di bangun atas dasar check and balance dan simbiosis mutualistis dimana agama memberikan nilai spiritual dan kerohanian di dalam tatanan kehidupan berbangsa dan bernegara dan negara menfasilitasi dan menjamin kehidupan keagamaan.
\end{abstract}

Kata Kunci: Agama, Negara dan Pancasila

\section{PENDAHULUAN}

Berdasarkan sensus penduduk dilakukan oleh Badan Pusat Statistik Tahun 2010, 237.641.326 penduduk Indonesia adalah pemeluk agama Islam $87,18 \%$, Kristen 6,96\%, Katolik 2,9\%, Hindu $1,7 \%$, Budha $0,7 \%$ dan Kong $\mathrm{Hu}$ $\mathrm{Cu} 0,05 \%{ }^{1}$. Sebagai salah satu negara berpenduduk Muslim terbesar di dunia, Indonesia merupakan negara yang unik dalam konteks agama dan negara. Sebagai negara yang penduduknya mayoritas Muslim, Pancasila terpilih sebagai dasar negara dan ideologi negara bukan ideologi lainnya. Pancasila terpilih sebagai dasar negara dan ideologi adalah untuk menjaga persatuan

1 Sensus Penduduk “ Menurut Wilayah dan Agama yang Di anut", Jakarta, Indonesia, Badan Statistik, 15 Mei 2010. dan kesatuan karena Indonesia memiliki keberagaman agama, suku, dan etnis. The founding fathers Indonesia memilih dan merumuskan suatu dasar filosofi yang sesuai dengan realitas bangsa ini, yakni suatu dasar filsafat bangsa dan negara di tengah-tengah negara ateis, sekuler dan negara teokrasi.

Secara yuridis Indonesia memiliki landasan yang kuat dalam kehidupan beragama sebagaimana tertuang sebagai dasar negara maupun tertuang dalam Undang-Undang Dasar 1945. Filsafat Negara Pancasila mengakui tentang Ketuhanan, sebagai dasar negara dan sumber dari segala sumber hukum yang ada di Indonesia. Ciri dari negara Berketuhanan Yang Maha Esa adalah adanya jaminan terhadap masyarakat untuk memeluk agama dan menjalankan 
ibadah berdasarkan agama dan kepercayaannya.

Menghadapi era globalisasi seharusnya bangsa Indonesia merapatkan barisan untuk menangani permasalahan kemiskinan, meningkatkan kesejahteraan rakyat, meningkatkan mutu pendidikan dan kesehatan serta hukum bukan kembali kepersoalan kebangsaan yang seharusnya sudah kita pahami dan tidak menjadi sumber berdebatan lagi. Sebagai contoh adalah persoalan keagamaan di negara Indonesia yang majemuk dan pluralis yang berlandaskan Ketuhanan Yang Maha Esa yang akhi-akhir ini menunjukan sikap kurang dewasa sebagian masyarakat. Seperti kasus Ambon, kasus Sampit, kasus Poso dan yang paling menyita perhatian masyarakat luas saat ini adalah pemilihan kepala daerah yang membawa isu agama di dalamnya. Nilai ketuhanan dalam kehidupan kebangsaan saat ini semakin menunjukkan kerancuan derivative ( penjabaran secara 'das sein' di dalam masyarakat secara objektif menimbulkankesimpangsiuran, dan nampak dalam derivasi normatif yuridis belum menunjukkan esensi negara yang berke-Tuhanan Yang Maha Esa.) seharusnya kita memantapkan kesakralan dan karakter Pancasila, sehingga Pancasila mengisyaratkan bahwa kesadaran Tuhan bukan milik siapapun secara khusus. Pancasila menterminologikan Tuhan sebagai Tuhan Yang Maha Esa yang tak terbagi yang mampu melingkupi Islam, Kristen, Katolik, Hindu, Budha dan Kunghucu.

\section{METODE}

Penelitian menggunakan pendekatan yuridis normatif karena dalam penelitian ini melihat masalah hukum sebagai kaidah yang dianggap sesuai dengan penelitian yuridis normatif. Penelitian yuridis normatif dilakukan terhadap halhal yang bersifat teoritis yaitu suatu pendekatan yang dilakukan melalui studi perpustakaan (library research) dengan mempelajari asas-asas hukum yang ada dalam teori atau pendapat sarjana dan peraturan perundang-undangan yang berlaku. Dalam konteks ini focus penelitian adalah relasi negara dan agama dalam perseptif Pancasila.

\section{ANALISIS HASIL DAN PEMBAHASAN}

Sejarah merumuskan dasar filsafat negara Indonesia tidak berjalan mudah dan mengalami perdebatan hal ini dilatarbelakangi karena Indonesia memiliki beranekaragam suku, etnis, ras, agama serta golongan politik. Perdebatan tentang dasar filsafat negara di mulai dari sidang BPUPKI pertama di mulai pada tanggal 29 Mei-1 Juni 1945. Usulan pertama disampaikan Muhammad Yamin pada tanggal 29 Mei mengajukan dasar negara yang terdiri 5 hal yaitu Peri Kebangsaan, Peri Kemanusian, Peri Ketuhanan, Peri Kerakyatan dan Kesejahteraan Rakyat. Usulan kedua disampaikan Soepmo pada tanggal 31 Mei 1945 mengusulkan lima dasar negara yaitu: paham Negara Kesatuan, Perhubungan Negara dan Agama, Sistem Badan Permusyawaratan, Sosialisme 
Negara dan Hubungan Antarbangsa. Soekarno pada tanggal 1 Juni 1945 mengajukan usul tentang dasar negara yang terdiri dari lima hal yaitu: Nasionalisme, Internasionalisme, Mufakat atau Demokrasi, Kesejahteraan Sosial dan Ketuhanan Yang Berkebudayaan yang kelima hal tersebut di beri nama Pancasila. Pada tanggal 22 Juni 1945 di adakan rapat gabungan antara panitia kecil dengan anggota BPUPKI yang berhasil merumuskan calon Mukadimah Hukum Dasar yang di kenal sebagai "Piagam Jakarta atau Jakarta Charter". Pada tanggal 17 Agustus setelah upacara kemerdekaan datang beberapa utusan dari wilayah Indonesia Bagian Timur yang ingin menyampaikan keberatan akan sila pertama Pancasila "Ketuhanan dengan Kewajiban Menjalankan Syariat Islam bagi Pemeluk-Pemeluknya" karena merasa tidak di akomodasi kepentingannya dan ingin memisahkan diri jika tetap dipertahankan rumusan tersebut. Pada sidang PPKI 1 pada tanggal 18 Agustus, Muh. Hatta mengusul untuk merubah tujuh kata dari sila pertama Pancasila menjadi "Ketuhanan Yang Maha Esa" pengubahan tersebut telah dibicarakan dengan 4 orang tokoh Islam (Kasman Simgodimejo, Wahid Hasyim, Ki Bagus Hadikusumo dan Teuku M. Hasan) dan mereka menyetujui perubahan kalimat tersebut demi persatuan dan kesatuan bangsa.

Peristiwa perubahan tujuh kata dari sila pertama merupakan peristiwa bersejarah yang penuh dengan pesan moral bahwa persatuan dan kesatuan diutamakan dari kepentingan pribadi dan golongan.Pancasila yang di dalamnya terkandung dasar filsafat hubungan negara dengan agama, adalah merupakan karya besar bangsa Indonesia melalui "The Founding Fathers" Negara Republik Indonesia.Konsep pemikiran para pendiri negara yang tertuang dalam Pancasila, merupakan karya yang khas yang secara antropologis merupakan "local genius" bangsa Indonesia. ${ }^{2}$

\section{A. Makna "Ketuhanan Yang Maha Esa" dalam Kehidupan Bernegara}

Negara Pancasila mengakui tentang ketuhanan, sebagai dasar negara dan sumber dari segala sumber hukum yang ada di Indonesia.Indonesia bukan juga merupakan negara sekuler yang memisahkan antara urusan agama dengan urusan negara.Indonesia adalah Negara Pancasila yang religius yang melindungi dan memfasilitasi perkembangan agama yang di peluk oleh warga negaranya tanpa membedakan besar atau kecil jumlah pemeluk. Ini yang menjadi pembeda bangsa Indonesia dengan bangsa lain. Nilai-nilai yang terdapat dalam Pancasila berasal dari agama-agama yang ada di Indonesia serta budaya manusia Indonesia. Sehingga setiap umat beragama hendaknya memahami filsafat Pancasila sejalan dengan nilai-nilai ajaran agama yang di yakini dengan demikian, timbul kenyakinan bahwa lima sila di dalam Pancasila selaras dengan agama yang

${ }^{2}$ Ayatrohaedi, 1986, Kepribadian Budaya Bangsa:Local Genius, Jakarta: Pustaka Jaya, 
hidup dimasyarakat. Masyarakat dapat menghindari adanya perasaan kesenjangan antara meyakini dan mengamalkan ajaran agama serta untuk menerima Pancasila sebagai filsafat negara. Dengan di terimanya Pancasila oleh seluruh warga Negara Indonesia maka tidak ada lagi pertentangan antara nilai-nilai Pancasila dengan agama manapun. Secara yuridis Indonesia memiliki landasan yang kuat dalam kehidupan beragama sebagaimana tertuang sebagai dasar negara maupun tertuang dalam Undang-Undang Dasar 1945. Filsafat Negara Pancasila mengakui tentang Ketuhanan, sebagai dasar negara dan sumber dari segala sumber hukum yang ada di Indonesia. Ciri dari negara Ketuhanan Yang Maha Esa adalah adanya jaminan terhadap masyarakat untuk memeluk agama dan menjalankan ibadah berdasarkan agama dan kepercayaannya. Agus Salim berpendapat Ketuhanan Yang Maha Esa menjadi prinsip dasar dalam kehidupan bersama berbagai pemeluk agama Negara Republik Indonesia. Dalam kehidupan bersama ini negara maupun semua paham dan aliran agama tidak dibenarkan masuk pada ruang pribadi akidah masing-masing orang. ${ }^{3}$ Ini yang menjadi pembeda bangsa Indonesia dengan bangsa lain, bangsa Indonesia bukan negara yang berdasarkan agama tertentu, Indonesia bukan juga merupakan negara sekuler yang

3 Roem, Muhammad, dan Agus Salim, Ketuhanan Yang Maha Esa dan Lahirnya Pancasila. Jakarta: Bulan Bintang.1997 mimisahkan antara urusan agama dengan urusan negara.

Makna sila pertama dalam Pancasila yang berbunyi "Ketuhanan Yang Maha Esa" mengandung arti bahwa Pancasila mengakui dan mensakralkan keberadaan agama, bukan hanya Islam namun termasuk Kristen, Budha, Hindu dan Konhucu sebagai agama resmi Bangsa Indonesia. Jika dijelaskan kesimpulan dari sila Ketuhanan Yang Maha Esa adalah pertama: Tuhan merupakan kausa yang tertinggi, mutlak dan abadi, merupakan asal mula segala sesuatu, tidak terbatas, tidak berubah serta pengatur tata tertib alam sehingga harus ditaati di samping itu pula "Ketuhanan Yang Maha Esa" menjadi roh atau spirit dari keutuhan Negara Kesatuan Republik Indonesia (NKRI). Kedua: di dalam Negara Indonesia tidak boleh terjadi pertentangan dalam hal ketuhanan atau anti agama, tidak boleh ada paksaan agama , diskriminasi dan dalam Negara Indonesia di bangun sikap toleransi yang tinggi terhadap agama yang berbeda. Ketiga: Ketuhanan Yang Maha Esa adalah ketuhanan yang berkemanusian yang adil dan beradab, yang berpersatuan Indonesia, yang berkerakyatan yang dipimpin oleh hikmat kebijaksanaan dalam permusyawaratan /perwakilan dan yang berkeadilan sosial bagi seluruh rakyat Indonesia. Ke empat: Negara mempunyai kewajiban untuk melindungi, menjaga kerukunan hidup beragama dan membantu semua agama yang di akui di Indonesia tanpa ada pengecualiaan. 
Volume 1 Nomor 1

Kata sepakat tentang dasar negara mengenai Ketuhanan Yang Maha Esa, berarti bahwa masing-masing percaya kepada Tuhan menurut agamanya sendiri-sendiri, dengan kesadaran bahwa bersama kita dapat mendirikan negara yang kuat sentausa karena esensi dari agama, ialah hidup berbakti, menjunjung keadilan, cinta dan kasih sayang terhadap sesama makhluk. ${ }^{4}$ Diharapkan setelah memaknai sila pertama "Ketuhanan Yang Maha Esa" masyarakata Indonesia dapat menyadari bahwa sebagai bangsa Indonesia yang memiliki berbagai macam suku, budaya dan agama masyarakat kita di tutut untuk dapat saling menghormati, menyayangi dan menghormati antara satu suku dengan suku lainnya, antara satu budaya dengan budaya lainnya dan antara satu agama dengan agama lainnya agar timbul kerukunan dan kedamaian di negara Indonesia. Di samping itupula masyarakat Indonesia memiliki prinsip Ketuhanan dalam bernegara yang dimana tindakan setiap manusia di minta pertanggungjawaban di akhirat kelak. Sehingga dalam Jika masyarakat Indonesia memegang prinsip "Negara berdasar atas Ketuhanan Yang Maha Esa" maka negara tidak akan memberikan kesempatan pada terjadinya korupsi, konflik horizontal, kerusakan lingkungan, dan lain-lain yang melanggar Prinsip Ketuhanan Yang Maha Esa.

${ }^{4}$ Roem, Mohammad, dan Agus Salim, 1977, Ketuhanan Yang Maha Esa dan Lahirnya Pancasila, Bulan Bintang, Jakarta. Hlm 116).

\section{B. Relasi Negara dan Agama dalam Perseptif Pancasila}

Relasi antara agama dan negara di Indonesia mengalami masa pasang surut.Ada kala nya relasi keduanya berjalan sangat harmonis dan ada kalanya mengalami permasalahan. Permasalahan yang sering timbul yang mempengaruhi relasi negara dan agama adalah ketika negara tidakdapat memberikan kemerdekaan dan menfasilitasi kepada warga negaranya untuk beribadat sesuai dengan agamanya masing-masing, atau saat agama menganggaptatanan kenegaraan berjalan bertentangan dengan nilai-nilai agama dikarenakan negara menutup diri terhadap nilai-nilai keagamaan. Dalam situasi seperti ini terbuka peluang negara akan melakukan tindakan represif terhadap warga negaranya tanpa memperhatikan ajaran agama berkaitan dengan persamaan di hadapan Tuhan dan keadilan atau agama berupaya mempengaruhi instrument kenegaraan tanpa memperhatikan asas-asas demokrasi yang di anut oleh bangsa Indonesia. Agar tidak terjadi ketegangan di Indonesia, maka aparatur negara harus menyadari bahwa dalam mengelola negara nilai-nilai keagamaanharus memperhatikan, sementara itu tokoh agama dalam melakukan internalisasi nilai-nilai keagamaanharus menyadari bahwadalam kehidupan berbangsa dan bernegara harus memperhatikan nilainilaipersatuan, persaudaraan dan demokrasi.

Sejarah perjalanannya relasi antara negara dan agama terkadang mengalami 
"godaan agama memanfaatkan politik dan "godaan politik memanfaatkan agama". Memanfaatkan adalah hal yang manusiawi tapi harus diwaspadai jika dua kekuatan besar ini agama dan negara mengancam persatuan dan kesatuan yang sudah susah payah di bina. Ketika negara diperalat oleh agama, maka negara akan cendrung totaliter yang eksklusif dan diskriminatif disamping itupula ketika agama menjadi alat politik maka agama akan kehilangan jati diri dan fungsinya yang luhur sebagai agama. Secara tegas dinyatakan bahwa Indonesia bukan negara agama melainkan negara hukum. Hukum menjadi panglima, dan kekuasaan tertinggi, yang dapat diartikan bahwa Undang-Undang di buat oleh lembaga legislatif yaitu Dewan Perwakilan Rakyat (DPR) dan anggota DPR terdiri dari perwakilan dari berbagai suku,etnis dan agama. Hukum di Indonesia tidak di buat oleh kelompok agama, begitupun sebaliknya. $^{5}$

Terdapat tiga landasan yang berlaku bagi relasi agama dan negara dalam perseptif Pancasila yaitu: a. Asas inklusif dan non diskriminatif adalah semua agama mempunyai hak dan kewajiban yang sama dalam konstitusional dan negara mempunyai kewajiban dalam melindungi dan menfasilitasi tanpa membeda-bedakan, b. Asas kerukunan dan kerukunan beragama adalah kebebasan tidak boleh mematikan

${ }^{5}$ Lukman Hakim Saifuddin, 2009, Makalah untuk"Kongres Pancasila. Universitas Gajah Mada, Yogyakarta: hlm 10 kerukunan dan sebaliknya kerukunan tidak boleh mematikan kebebasan), c. Asas kemitraan yang sejajar dan timbal balik adalah negara mengakui otonomi agama dan sebaliknya, masing-masing tidak mencampuri langsung urusan otoritas. (negara hanya mempunyai untuk melindungi, menjamin dan membantu agar semua agama dapat hidup dan berkembang begitupun agama berkewajiban meletakkan landasan moral, spiritual dan etika bagi pembangunan nasional sebagai pengamalan pancasila).

Dibutuhkan arah kebijkan pembangunan di bidang agama agar tatanan kehidupan negara dan agama berjalan dengan baik sehingga relasi diantara keduanya tidak terjadi gejolak. Arah kebijakan pembangunan di bidang agama antara lain:

1. Memantapkan fungsi, peran dan kedudukan agama dalam penyelenggaraan negara serta mengupayakan agar segala peraturan perundang-undangan tidak bertentangan dengan moral agama yang di anut warga negara.

2. Meningkatkan kualitas pendidikan agama melalui penyempurnaan sistem pendidikan agama secara terpadu dengan dengan di dukung oleh sarana dan prasarana yang memadai.

3. Meningkatkan dan memantapkan kerukunan hidup antar umat beragama sehingga tercipta kehidupan yang harmonis dan saling mrnghargai dalam semangat 
Volume 1 Nomor 1

kemajemukan melalui dialog antar umat beragama serta pelaksanaan pendidikan agama secara deskriptif yang tidak dogmatis.

4. Meningkatkan fasilitas dan kemudahan umat beragama dalam menjalankan ibadahnya.

5. Meningkatkan peran dan fungsi lembaga-lembaga keagamaan dalam mengatasi perubahan yang terjadi dalam aspek kehidupan bernegara.

Relasi antara negara dan agama dibangun atas dasar check and balance (saling mengontrol dan mengimbangi) dalam konteks ini kecendrungan negara untuk bertindak hegemonic sehingga terjerumus bertindak represif kepada warga negaranya dapat di kontrol dan di imbangi oleh ajaran agama yang mengutamakan menebarkan rahmat bagi seluruh umat di seluruh alam semesta dan menjujung hak asasi manusia. Saat agama disalahgunakan sebagai landasan praktek otoritarianisme harus dikontrol oleh peraturan dan norma yang yang ada di Indonesia. Disamping itu relasi antara negara dan agama harus bersifat simbiosis mutualistis dimana agama memberikan nilai spiritual dan kerohanian di dalam tatanan kehidupan berbangsa dan bernegara dan negara menfasilitasi dan menjamin kehidupan keagamaan. Jika diaktualisasikan dengan nyata di kehidupan bernegara relasi agama dan negara akan terjalin erat dan Indonesia menjadi negara yang religious yang rukun dan damai serta yang dapat melindungi semua agama yang di peluk tanpa membedakan besar atau kecilnya jumlah pemeluk.

\section{IV.PENUTUP}

Sebagai salah satu negara berpenduduk Muslim terbesar di dunia, Indonesia merupakan negara yang unik dalam konteks agama dan negara. Sebagai negara yang penduduknya mayoritas Muslim, Pancasila terpilih sebagai dasar negara dan ideologi agama tertentu. Makna sila "Ketuhanan Yang Maha Esa "Indonesia bukan negara yang berdasarkan agama tertentu, Indonesia bukan juga merupakan negara sekuler yang mimisahkan antara urusan agama dengan urusan negara. Indonesia adalah Negara Pancasila yang religius yang melindungi dan memfasilitasi perkembangan agama yang di peluk oleh warga negaranya tanpa membedakan besar atau kecil jumlah pemeluk.Relasi negara dan agama di bangun atas dasar check and balance dan simbiosis mutualistis dimana agama memberikan nilai spiritual dan kerohanian di dalam tatanan kehidupan berbangsa dan bernegara dan Negara menfasilitasi dan menjamin kehidupan keagamaan.

\section{DAFTAR BUKU}

Asshiddiqie, J., 2008. Mепији Negara Hukum yang Demokratis. Jakarta: Sekretariat Jendral dan Kepaniteraan.

Ghazali Abd.Moqsith. 2009. Argumen Pluralisme Agama. Jakarta: Kata Kita 
Kaelan, M.S., 2002. Filsafat Pancasila Pandangan

Hidup

Bangsa.Yogyakarta: Paradigma.

Mahfud, M.D., 1999."Pancasila sebagai Paradigma Pembaharuan Hukum", dalam Jurnal Filsafat Pancasila, Pusat Studi Pancasila Universitas Yogyakarta: Gadjah Mada.

Nasution, Adnan Buyung, 1995. Aspirasi Pemerintahan Konstitusional di Indonesia, Jakarta: Pustaka Utama Grafiti.

Roem, Mohammad, dan Agus Salim, 1977. Ketuhanan Yang Maha Esa dan Lahirnya Pancasila. Jakarta: Bulan Bintang.

Sastrapratedja, M., 1996, Pancasila dan Globalisasi, dalam Seminar Nasional Pendidikan Pancasila, diselenggarakan atas kerjasama Forum Komunikasi Dosen Pancasila (FKDP) Propinsi Jawa Tengah dengan Universitas Tidar Magelang, Magelang 29-31 Juli 1996. 